\title{
HUBUNGAN ANTARA PENGETAHUAN MENYELAM DENGAN GANGGUAN PENDENGARAN PADA PEKERJA BAWAH AIR DI PERUSAHAAN KONSTRUKSI BAWAH LAUT
}

\author{
RELATIONSHIP BETWEEN DIVING KNOWLEDGE WITH HEARING \\ LOSS ON UNDERWATER WORKERS IN UNDERWATER CONSTRUCTION \\ COMPANY
}

\author{
Eka Senja Koesdianasari \\ PT. Trijaya Global Marindo \\ E-mail: eka.senja-13@fkm.unair.ac.id
}

\begin{abstract}
Underwater workers were prone to hearing loss. Pressure during diving and depth of dive were causing hearing loss.Jobs that are at risk for barotrauma are divers, keepers or pearl takers, marine boat keepers, rescue teams, and underwater construction work. Diving which requires a longer dive duration and deeper depth is very susceptible to health problems such as damage to the lungs, brain hemorrhage, gas poisoning and loss of body heat. This study aims to learn relationship between dive knowledge and hearing loss. The design of this research is a cross sectional study. This research is a descriptive research, because this research is the whole population. This was observational study carried out from April until June 2017 used cross sectional method. The dependent variable in this study is hearing loss, while the independent variable is diving knowledge. The result showed that obtained from 6 respondents, 100\% of the respondents with bad knowledge suffer from moderate hearing loss, $60 \%$ of the respondents with sufficient knowledge suffer from mild hearing loss and $40 \%$ of the respondents with sufficient knowledge do not suffer from hearing loss. Contingency coefficient statistical test results indicate that there is a relationship between diving knowledge and hearing loss in PT Aquamarine Divindo Inspection Sidoarjo. The better knowledge can affect the respondent's hearing loss. The conclusion in this study is the Ambang Listen Value using the audiometry test most respondents are mild deaf.
\end{abstract}

Keywords: audiometric, hearing loss, underwater construction, underwater workers

\begin{abstract}
ABSTRAK
Pekerja di bawah air rentan terhadap gangguan pendengaran. Tekanan saat menyelam dan kedalaman menyelam menyebabkan gangguan pendengaran. Pekerjaan yang berisiko barotrauma adalah penyelam, pemelihara atau pengambil mutiara, pemelihara kapal laut, tim penyelamat, dan pekerjaan konstruksi bawah laut. Penyelaman yang membutuhkan durasi selam penyelaman lebih lama dan kedalaman yang lebih dalam sangat rentan terjadi gangguan kesehatan seperti terjadinya kerusakan pada paru paru, pendarahan otak, keracunan gas dan kehilangan panas tubuh. Tujuan penelitian ini untuk mempelajari gangguan pendengaran pada pekerja bawah air yang dilihat dari pengetahuan menyelam para pekerja bawah air. Penelitian ini merupakan penelitian deskriptif, karena penelitian ini menggambarkan keseluruhan populasi. Penelitian diambil pada April sampai Juni 2017 menggunakan metode cross sectional. Variabel dependen pada penelitian ini adalah gangguan pendengaran, sedangkan variabel independen nya adalah pengetahuan menyelam. Hasil dari penelitian adalah dari total 6 orang responden, 100\% responden dengan pengetahuan buruk mengalami gangguan pendengaran tuli sedang, 60\% berpengetahuan baik mengalami gangguan pendengaran tuli ringan, dan $40 \%$ responden dengan pengetahuan baik tidak mengalami gangguan pendengaran. Hasil uji statistik koefisien kontingen, menunjukkan bahwa terdapat hubungan antara pengetahuan menyelam dengan gangguan pendengaran di PT Aquamarine Divindo Inspection Sidoarjo. Pengetahuan yang semakin baik dapat memengaruhi responden terkena gangguan pendengaran. Kesimpulan dalam penelitian ini adalah Nilai Ambang Dengar (NAD) menggunakan tes audiometri sebagian besar responden adalah tuli ringan.
\end{abstract}

Kata kunci: audiometri, gangguan pendengaran, pekerja bawah air, konstruksi bawah air 


\section{PENDAHULUAN}

Negara Indonesia memiliki 2/3 luas wilayah berupa lautan, dengan keadaan tersebut sangat terbuka untuk pemanfaatan laut sebagai sarana tempat kerja bagi pekerja nya. Industri maritim merupakan tempat kerja khusus dengan cara kerja di laut dan berhubungan dengan lautan (Suma'mur, 1991). Industri maritim semakin berkembang, berbagai kegiatan pengeksplorasian kekayaan laut telah sering dilakukan, kegiatan pengeksplorasian kekayaan laut antara lain penangkapan ikan oleh nelayan, pemanfaatan laut sebagai sarana transportasi dan pengeksplorasian kekayaan bawah laut seperti eksploitasi minyak bumi dan gas dengan cara penyelaman.

Risiko pekerjaan dalam penyelaman sangat bervariasi. Risiko penyelaman tergantung dari jenis pekerjaannya. Terdapat berbagai macam jenis penyelaman, yaitu penyelam tradisional dan penyelam modern (Ekawati, 2005). Penyelam tradisional biasanya bekerja sebagai nelayan, berisiko tinggi terkena penyakit akibat kerja karena kurang lengkap dan tidak aman peralatan yang digunakan. Penyelam modern juga rentan terkena penyakit akibat kerja karena ketidaktahuan dalam memakai peralatan yang digunakan.

Pusat Data dan Informasi Kementerian Tenaga Kerja dan Transmigrasi RI (Jamsostek) hingga Agustus 2012, penduduk Indonesia yang bekerja sebanyak 110.808.154 orang. Pada tahun 2011 tercatat 96.314 kasus kecelakaan kerja dan penyakit akibat kerja dengan korban meninggal 2.144 orang dan mengalami cacat sebanyak 42 orang. 3 kasus kecelakaan kerja dan penyakit akibat kerja tahun 2012. Meskipun demikian data tersebut diatas tidak menjelaskan jumlah keseluruhan kasus kecelakaan dan penyakit akibat kerja yang terjadi di Indonesia, tersebut meningkat menjadi 103.000 kasus per tahunnya (Sukbar dkk, 2016).

Gangguan pendengaran dapat terjadi karena berbagai faktor. Gangguan pendengaran dapat didefinisikan sebagai kurangnya atau sulitnya menerima rangsangan bunyi atau suara. Atau dapat dikatakan bahwa gangguan pendengaran adalah ketidakmampuan secara sebagian ataupun keseluruhan untuk mendengarkan suara pada salah satu maupun kedua telinga (Susanto, 2010). Gangguan pendengaran dapat diakibatkan oleh banyak faktor misalnya suara keras atau bising, infeksi pada telinga, adanya binatang kecil yang masuk ke dalam telinga, dan adanya perbedaan tekanan dari dalam tubuh dan luar tubuh yang cukup ekstrem.

Organ yang berperan untuk fungsi pendengaran adalah telinga. Telinga selain berfungsi untuk pendengaran juga berfungsi untuk keseimbangan. Secara anatomis telinga terbagi menjadi telinga luar (auris externa), telinga tengah (auris media) dan telinga dalam (auris interna). Telinga luar berperan seperti mikrofon yaitu mengumpulkan bunyi dan meneruskan nya melalui saluran telinga (canalis acusticus externus) menuju telinga tengah dan telinga dalam. Getaran yang sampai ke telinga dalam selanjutnya akan diubah menjadi rangsang listrik yang selanjutnya akan dikirim ke pusat pendengaran di otak.

Jumlah orang di seluruh dunia dengan semua tingkat gangguan pendengaran meningkat terutama disebabkan meningkatnya populasi global dan usia harapan hidup. Persentase prevalensi gangguan pendengaran pada populasi penduduk secara umum bervariasi dari minimal 4,2\% di Indonesia hingga 9\% di Sri Lanka, 13,3\% di Thailand dan 16,6\% di Nepal. Berdasarkan angka tersebut, terdapat lebih dari 100 juta orang yang menderita masalah ketulian dan gangguan pendengaran di kawasan Asia Timur.

Menurut Undang-undang No 1 Tahun 1970 pasal 8 ayat 1, pengurus diwajibkan memeriksakan kesehatan badan, kondisi mental dan kemampuan fisik dari tenaga kerja yang akan diterimanya maupun akan dipindahkan sesuai dengan sifat-sifat pekerjaan yang diberikan padanya. Dan pengurus diwajibkan memeriksa semua tenaga kerja yang berada di bawah pimpinannya, secara berkala pada Dokter yang ditunjuk oleh Pengusaha dan dibenarkan oleh Direktur.

Beberapa penelitian di luar Indonesia menunjukkan bahwa penyelam paling sering mengalami gangguan pendengaran. Sebuah studi pada 429 penyelam professional di Iran menunjukkan gangguan yang paling sering otitis eksternal 43,6\% (Kristianto, 2012). Sebuah penelitian di Eropa didapatkan dari 142 penyelam, $64 \%$ melaporkan gejala barotrauma, tuli sementara akibat tinnitus $27,5 \%$ dan mengalami vertigo 9,9\% (Kristianto, 2012).

Pekerjaan menyelam yang membutuhkan durasi kerja penyelaman lebih lama dan kedalaman yang lebih dalam, teknik dan peralatan yang digunakan berbeda (Rijadi, 2009). Penyelaman yang membutuhkan durasi selam penyelaman 
lebih lama dan kedalaman yang lebih dalam sangat rentan terjadi gangguan kesehatan seperti terjadinya kerusakan pada paru paru, pendarahan otak, keracunan gas dan kehilangan panas tubuh. Hal tersebut dikarenakan suhu air laut yang lebih dingin, tekanan air terhadap tubuh yang lebih besar, terbatasnya udara pernafasan dan adanya ancaman dari binatang laut berbahaya yang ada di laut dalam (Lazwar, 2015).

Data yang dikumpulkan Dit Sepim Kesma Depkes sampai dengan tahun 2008, dari 1.026 penyelam ditemukan $93,9 \%$ penyelam pernah menderita gejala awal penyakit penyelaman, yaitu sebanyak 29,8\% menderita nyeri sendi 39,5\% menderita gangguan pendengaran dan 10,3\% menderita kelumpuhan, yang sebagian besar diantaranya adalah penyelam tradisional.

Pekerjaan yang berisiko barotrauma adalah penyelam, pemelihara atau pengambil mutiara, pemelihara kapal laut, tim penyelamat, dan pekerjaan konstruksi bawah laut. Pengambilan data dilakukan di PT Aquamarine Divindo Inspection Sidoarjo karena pada perusahaan tersebut belum ada program pemeriksaan kesehatan berkala untuk pekerja bawah air. Tetapi memang belum adanya data yang menunjukkan bahwa di perusahaan tersebut banyak pekerja yang mengalami gangguan pendengaran. Itulah sebabnya penelitian ini dilakukan guna untuk melihat kesehatan para pekerja bawah air di PT Aquamarine Divindo Inspection Sidoarjo.

Berdasarkan data kasus kecelakaan kerja yang telah diperoleh diatas, peneliti tertarik untuk mengetahui hubungan pengetahuan menyelam dengan gangguan pendengaran pada pekerja bawah air di PT Aquamarine Divindo Inspection Sidoarjo. Alasan peneliti mengambil data di perusahaan tersebut adalah karena menurut pengambilan data awal bahwa perusahaan tersebut belum menerapkan pemeriksaan kesehatan berkala, sementara di undang-undang No.1 tahun 1970 sudah diatur bahwa perusahaan yang memiliki risiko pekerjaan tinggi wajib menerapkan pemeriksaan kesehatan berkala minimal 1 tahun periode.

\section{METODE}

Rancang bangun penelitian ini merupakan penelitian cross sectional. Penelitian ini merupakan penelitian deskriptif, karena penelitian ini menggambarkan keseluruhan populasi. Peneliti tidak melakukan perlakuan terhadap subjek penelitian, sehingga penelitian ini masuk ke dalam jenis penelitian observasional. Penelitian ini termasuk dalam jenis penelitian lapangan karena penelitian dilakukan langsung pada tempat subjek berada.

Lokasi penelitian dilakukan pada PT. Aquamarine Divindo Inspection Sidoarjo, yakni sebuah perusahaan yang bergerak di bidang konstruksi bawah air yang memiliki head office di Sidoarjo. Waktu untuk penelitian ini dimulai pada November 2016 hingga April 2017. Pengambilan data pada tempat penelitian dimulai pada Mei 2017.

Populasi dari penelitian ini merupakan keseluruhan populasi dari pekerja bawah air yang meliputi operation bawah air, teknisi bawah air, dan pengelas bawah air. Keseluruhan populasi pada penelitian ini berjumlah 6 orang.

Variabel penelitian ini terbagi menjadi dua jenis, yakni variabel dependen atau variabel terikat dan variabel independen atau variabel bebas. Variabel dependen pada penelitian ini adalah gangguan pendengaran, sedangkan variabel independennya adalah pengetahuan menyelam.

Cara pengumpulan data adalah peneliti menggunakan kuesioner yang akan diisi oleh pekerja bawah air. Tes audiometri untuk mengetahui derajat pendengaran. Penelitian ini menggunakan data primer yang didapatkan dari hasil kuesioner yang diisi oleh subjek penelitian. Analisis data yang digunakan adalah menggunakan metode uji chi-square untuk melihat hubungan antara variabel dependen dengan variabel independen.

\section{HASIL}

\section{Gambaran Umum PT. Aquamarine Divindo Inspection Sidoarjo}

Perusahaan yang bergerak di bidang inspeksi bawah air, dan konstruksi bawah air, PT. Aquamarine Divindo Inspection adalah perusahaan multinasional yang berdiri sejak tahun 2007 telah memiliki banyak pengalaman dalam bidangnya. Hal ini dibuktikan dengan banyaknya sertifikasi dan penghargaan yang didapatkan. Pengakuan dan keanggotaan profesional yang relevan telah diberikan untuk International Marine Contractors Association (IMCA), dan Association of Diving Contractor International (ADCI) sebagai anggota umum. PT Aquamarine Divindo Inspection memiliki kurang lebih 30 orang karyawan. 


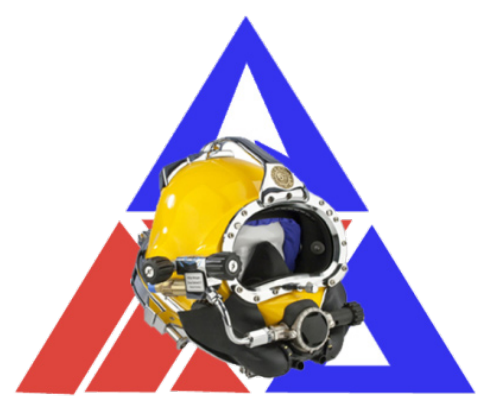

Gambar 1. Logo PT Aquamarine Divindo Inspection Sidoarjo

Pada gambar 1, merupakan logo dari PT Aquamarine Divindo Inspection. Logo tersebut memiliki makna yaitu keahlian dari perusahaan yang ahli dalam bidang pekerjaan bawah air yang dilambangkan dengan segitiga berwarna biru dan alat penyelaman yang disebut KMB (Kirby Morgan) Band Mask. Segitiga dengan tiga garis merah menunjukkan semangat perusahaan untuk terus melakukan pengembangan agar dapat menjadi perusahaan yang terdepan dalam bidang pekerjaan bawah air. Tulisan PT Aquamarine Divindo Inspection merupakan nama dari perusahaan yang diikuti dengan tulisan di bawahnya yaitu "Underwater Construction and Marine Service" yang mempertegas bahwa PT Aquamarine Divindo Inspection sangat unggul dalam pekerjaan bawah air.

\section{Macam-Macam Jenis Penyelaman}

Scuba diving merupakan kegiatan di bawah permukaan air yang dilakukan dengan alat bantu untuk bernafas di dalam air yaitu Self Contained Underwater Breathing Apparatus (SCUBA). Sistem ini pertama kali dirancang oleh Jacques Cousteau, udara yang bertekanan tinggi dimasukkan ke dalam tabung/tangki udara kemudian tekanannya dikurangi, dimampatkan, disaring dan dipompa sehingga bisa dihirup layaknya bernapas di atas permukaan air. Menyelam dengan scubacourse merupakan aktivitas yang banyak dilakukan oleh para penyelam deep diving, karena keterampilan diving course ini bisa digunakan untuk berbagai tujuan antara lain. Penyelaman scuba diving course untuk tujuan pertahanan dan keamanan negara, antara lain penyelaman untuk tugas-tugas tempur maupun kemanusiaan, seperti Search and Rescue (SAR). Penyelaman jenis ini banyak dilakukan oleh militer.
Penyelaman komersial (Commercial Diving), penyelaman deep diving course yang dilakukan oleh penyelam professional untuk melakukan kegiatan seperti konstruksi bawah air, penambangan lepas pantai, pengangkatan kapal tenggelam dan lain-lain. Untuk melakukan diving course ini dibutuhkan sekolah khusus untuk menjadi commercial diver. Penyelaman Ilmiah (Scientific diving), Diving course yang dilakukan untuk kepentingan ilmu pengetahuan yang ada di bawah air, seperti penelitian, biologi laut, geologi, kedokteran hiperbarik, arkeologi dan ilmu-ilmu kelautan lainnya. Penyelaman olah raga/ rekreasi (sport/recreation diving). Scuba course inilah yang paling banyak diminati, karena selain sebagai sarana olah raga juga untuk kepentingan rekreasi atau wisata bawah air.

PT. Aquamarine Divindo Inspection Sidoarjo termasuk dalam kategori penyelaman komersial (commercial diving). Penyelaman dilakukan dengan tujuan konstruksi bawah air dan dilakukan oleh professional yang sebelumnya mengetahui tata cara menyelam yang didapat dalam diving course atau sekolah khusus diver. PT. Aquamarine Divindo Inspection Sidoarjo menetapkan diperlukannya sertifikat khusus yang digunakan atau sebagai bukti bahwa dia pernah mengikuti sertifikasi pengelasan bawah laut dan ahli dalam hal tersebut, karena bila tidak ada sertifikasi atau mengikuti diving course terlebih dahulu pekerjaan pengelasan bawah laut dapat menyebabkan kecelakaan kerja yang fatal.

\section{Jenis Gangguan Pendengaran}

Gangguan pendengaran terbagi dalam beberapa kelompok besar, yaitu gangguan pendengaran konduktif, sensorineural, campuran, dan fungsional. Gangguan pendengaran konduktif, gangguan konduksi bunyi dari telinga luar ke telinga tengah menyebabkan gangguan pendengaran tipe konduktif. Gangguan ini terjadi ketika konduksi bunyi dengan hantaran udara terhambat. Etiologi gangguan ini diantaranya adalah dampak serumen, adanya benda asing pada kanal telinga, adanya tumor benigna pada telinga tengah, disfungsi tuba eustachius, karsinoma pada telinga luar, otitis media, kolesteatoma, dan otosklerosis. Gangguan pendengaran jenis ini masih dapat dikoreksi dengan pembedahan. Mekanisme terjadinya gangguan pendengaran tipe ini adalah penurunan transmisi bunyi dari luar telinga menuju ke koklea. Etiologi tersering adalah otosklerosis dan kolesteatoma, yaitu timbulnya kista yang bersifat 
lokal dan jinak. Suara yang diterima oleh otak berkurang, namun tidak terdistorsi.

Gangguan pendengaran sensorineural, merupakan tipe gangguan pendengaran yang disebabkan oleh gangguan pada bagian telinga dalam, yaitu organ corti. Gangguan ini tidak dapat dikoreksi dengan cara apapun. Gangguan tipe ini terjadi karena adanya cedera atau gangguan pada jalur pendengaran setelah koklea. Hal tersebut bisa terjadi karena adanya kerusakan sel rambut pada koklea ataupun cedera serabut saraf pendengaran (Cranial Nerve VIII). Suara yang diterima oleh otak akan berkurang dan terdistorsi. Etiologi gangguan pendengaran sensorineural diantaranya penuaan (presbikusis), penyakit Ménière, zat ototoksik (contoh: arsen, etil, metal alkohol), penyakit sistemik (contoh: diabetes melitus), dan induksi bising. Noiseinduced hearing loss (NIHL) bisa disebabkan oleh dua hal, yaitu sebab okupasional atau sebab yang berhubungan dengan pekerjaan, dan juga sebab nonokupasional (Syafrudin, 2015).

Gangguan yang disebabkan oleh sebab okupasional lebih sering terjadi walaupun cara pencegahan nya tidak sulit. Gangguan pendengaran karena bising muncul perlahan setelah pajanan bising selama bertahun-tahun, pada pajanan yang stabil, gangguan ini mulai terjadi secara signifikan setelah 10tahun. Tes audiometri pada NIHL menunjukkan hasil tuli sensorineural pada frekuensi $3000-6000 \mathrm{~Hz}$, dengan efek paling besar pada 4000 Hz. Homberg memaparkan bahwa bunyi dengan intensitas $\geq 72 \mathrm{~dB}$ akan diartikan sebagai bunyi yang mengganggu oleh otak manusia walaupun dengan alat pelindung telinga. Dornie dan Lakssonen kemudian meneliti lebih jauh tentang bunyi yang dianggap mengganggu tersebut. Dari hasil penelitian didapatkan bahwa interpretasi kualitas bunyi yang mengganggu bisa saja memberikan peringatan bagi tubuh bahwa bunyi tersebut dapat mengganggu kesehatan, terutama kesehatan pendengaran. Sekresi kortisol urin menunjukkan peningkatan pada seseorang yang bekerja dengan bunyi yang tidak diinginkan. Kortisol urin menurun menjadi normal setelah tujuh hari peredaman bunyi tersebut.

Pajanan bising tidak hanya membuat sel rambut mati, tetapi juga membuat penyimpangan fungsi dari sel rambut yang masih hidup. Pada koklea yang terpajan bising juga ditemukan aktivitas apoptosis. Induksi terjadinya apoptosis ini mungkin saja distimulasi oleh signal kaskade Src-protein tyrosine kinase (PTK). Gangguan Pendengaran Campuran, Jenis gangguan ini terjadi karena kombinasi gangguan pendengaran konduktif dan juga sensorineural. Gangguan Pendengaran Fungsional, Gangguan jenis fungsional jarang terjadi. Gangguan jenis fungsional tidak disebabkan oleh kerusakan pada organ, namun faktor pencetusnya adalah kondisi emosi dan juga psikologis. Kurangnya konsentrasi dan perhatian pada saat tes audiometri dapat menyebabkan hasil gangguan pendengaran fungsional. Biasanya hal ini terjadi pada anak-anak.

\section{Jenis Pemeriksaan Pendengaran}

Tes untuk mengetahui adanya gangguan pendengaran pada seseorang, diantaranya adalah tes akuitas auditorius, tes audiometri,tes Rinne, dan tes Weber. Akuitas Auditorius adalah tes yang dilakukan untuk memperkirakan kemampuan pendengaran. Subjek pada pemeriksaan ini harus menutup salah satu lubang telinganya terlebih dahulu. Pemeriksa berdiri 1 atau 2 kaki $(0,3$ atau 0,6 meter) dari subjek penelitian, kemudian pemeriksa memulai tes ini sambil menutupi mulut agar subjek tidak membaca gerak bibir pemeriksa. Pemeriksa kemudian berbisik dengan perlahan ke arah telinga yang terbuka. Subjek tidak dapat mengulang kata yang dibisikkan oleh pemeriksa, maka pemeriksa boleh meningkatkan intensitas suaranya menjadi bisikan sedang dan bisikan keras.

Tes audiometri nada murni, bersifat akurat untuk skrining gangguan pendengaran dengan sensitivitas $92 \%$ dan spesifikasi $94 \%$, namun untuk melakukannya membutuhkan biaya yang cukup tinggi. Awal dari pemeriksaan ini adalah menjelaskan kepada subjek pemeriksaan untuk mengangkat tangan ataupun mengatakan ada atau tidak ada bunyi apabila pemeriksa telah menyalakan bunyi. Subjek pemeriksaan diminta untuk memakai headphone yang dihubungkan dengan alat listrik yang menghasilkan bunyi nada murni dari berbagai frekuensi, dan dapat diatur intensitasnya. Subjek diminta duduk dengan nyaman pada kursi yang menghadap $30^{\circ}$ dari pemeriksa dengan tujuan agar subjek tidak dapat melihat pemeriksa melakukan sesuatu atau tidak. Hal tersebut dilakukan untuk menghindari hasil palsu. Telinga manusia normal mampu mendengar bunyi dengan rentang frekuensi 20-20.000 Hz, dan frekuensi yang paling penting dalam percakapan sehari-hari adalah 500-2.000 Hz. Pemeriksaan ini adalah penunjang utama diagnostik fungsi pendengaran. Intensitas bunyi akan diturunkan secara berangsur-angsur dan tes akan diakhiri pada intensitas terendah yang dapat 
didengar oleh subjek pemeriksaan. Hasil dari tes audiometri nada murni dituangkan pada audiogram dengan angka dalam satuan desibel.

Tes Rinne dilakukan untuk melihat perbandingan antara hantaran tulang (bone conduction) dengan hantaran udara (air conduction). Alat yang dibutuhkan pada tes ini adalah garpu tala $512 \mathrm{~Hz}$. Keuntungan dari tes Rinne adalah murah nya biaya yang dikeluarkan, biaya pemeliharaan alat yang murah, tidak dibutuhkannya kalibrasi ataupun penyeteman, ukuran alat yang kecil memudahkan untuk membawanya bepergian. Tes ini memiliki spesifikasi 96\% namun memiliki sensitivitas rendah, yaitu 55\%. Prosedur tes Rinne dimulai dengan meletakkan dengan kuat ujung tangkai garpu tala pada tulang mastoideus setelah digetarkan. Tulang mastoideus berada di belakang telinga. Setelah responden tidak mendengar bunyi, garpu tala dipindah kan dengan cepat ke depan lubang telinga responden, kemudian pastikan apakah responden dapat mendengar bunyi tersebut. Hasil tes dikatakan normal atau terdapat tuli sensorineural apabila bunyi hantaran udara terdengar lebih lama dibandingkan hantaran tulang $(\mathrm{AC}>\mathrm{BC})$. Pada tuli konduktif, bunyi melalui hantaran tulang akan terdengar lebih lama atau sama dengan bunyi melalui hantaran udara ( $\mathrm{BC} \geq \mathrm{AC}) .7$ Tes Rinne dapat memberikan hasil false negative pada telinga yang menderita SNHL yang sedang di tes. Hal ini disebabkan karena stimulus BC dapat terdengar pada telinga yang tidak sedang di tes akibat adanya transmisi transkranial, sehingga $\mathrm{BC}$ akan terdengar seolah lebih keras dibandingkan AC. Oleh karena itu hasil tes Rinne pada pasien SNHL dan individu normal tidak dapat dibedakan, yang merupakan kelemahan tes ini.

Tes Weber ditujukan untuk melihat lateralisasi. Untuk melakukan tes ini dibutuhkan garpu tala 512 Hz. Sama halnya seperti tes Rinne, keuntungan dari tes Weber adalah murahnya biaya yang dikeluarkan, biaya pemeliharaan alat yang murah, tidak dibutuhkannya kalibrasi ataupun penyeteman, dan ukuran alat yang kecil memudahkan untuk membawanya bepergian. Tingkat akurasi tes ini tidak begitu tinggi, yaitu $60 \%$ pada sensitivitas dan $69 \%$ pada spesifikasi. Untuk memulai tes ini, garpu tala digetarkan terlebih dahulu kemudian diletakkan dengan kuat ujung tangkainya pada puncak kepala atau pada tengah dahi responden. Hasil yang normal adalah bunyi akan terdengar pada kedua sisi dan sama kerasnya. Pada tuli sensorineural unilateral, bunyi akan lateralisasi ke arah telinga yang tidak terganggu. Terdapat tuli konduktif unilateral, akan
Tabel 1. Klasifikasi Gangguan Pendengaran

\begin{tabular}{|c|c|c|}
\hline $\begin{array}{c}\text { Derajat } \\
\text { Pendengaran }\end{array}$ & $\begin{array}{c}\text { Tingkat } \\
\text { Gangguan }\end{array}$ & $\begin{array}{c}\text { Pengertian dan } \\
\text { Klasifikasi }\end{array}$ \\
\hline $0-25 \mathrm{~dB}$ & Normal & $\begin{array}{l}\text { Tidak ada kesulitan } \\
\text { yang signifikan } \\
\text { dengan percakapan } \\
\text { yang lemah }\end{array}$ \\
\hline $26-40 \mathrm{~dB}$ & Ringan & $\begin{array}{c}\text { Kesulitan dengan } \\
\text { percakapan yang } \\
\text { lemah }\end{array}$ \\
\hline $41-55 \mathrm{~dB}$ & Sedang & $\begin{array}{c}\text { Sering kesulitan } \\
\text { dengan percakapan } \\
\text { normal }\end{array}$ \\
\hline $56-70 \mathrm{~dB}$ & $\begin{array}{l}\text { Cukup } \\
\text { Parah }\end{array}$ & $\begin{array}{l}\text { Sering kesulitan } \\
\text { meskipun dengan } \\
\text { percakapan keras }\end{array}$ \\
\hline $71-90 \mathrm{~dB}$ & Parah & $\begin{array}{l}\text { Dapat memahami } \\
\text { teriakan saja atau } \\
\text { percakapan yang } \\
\text { diperkuat }\end{array}$ \\
\hline$>91 \mathrm{~dB}$ & $\begin{array}{l}\text { Sangat } \\
\text { Parah }\end{array}$ & $\begin{array}{l}\text { Biasanya tidak bisa } \\
\text { mengerti meskipun } \\
\text { percakapan diperkuat }\end{array}$ \\
\hline
\end{tabular}

terjadi lateralisasi ke arah telinga yang mengalami gangguan. Tes ini tidak dapat menentukan gangguan pendengaran bilateral.

Penelitian ini menggunakan tes audiometri yang merupakan tes yang dilakukan oleh dokter telinga. Tes ini menghasilkan derajat gangguan telinga yang dialami seseorang.

Penelitian yang dilakukan pada Mei 2017 yang dilaksanakan di PT. Aquamarine Divindo Inspection Sidoarjo menggunakan alat audiometri yang dilakukan dan dibantu oleh tenaga khusus yaitu seorang dokter dari salah satu lembaga yang ahli dalam bidangnya yaitu Laboratorium Ultra Medica. Pengambilan data responden yaitu dengan cara wawancara dan pemeriksaan telinga dilakukan dengan cara mengumpulkan para pekerja bawah air di perusahaan dan dilakukan tes audiometri di dalam ruangan kedap suara dengan cara bergantian. Responden berjumlah 6 orang yang bekerja di PT Aquamarine Divindo Inspection Sidoarjo sebagai pekerja bawah air yang meliputi operation bawah air, pengulas bawah air, dan teknisi bawah air.

Dari tabel 2 dapat dilihat bahwa responden terbanyak berada dalam pengetahuan menyelam dengan baik. Total jumlah 6 responden dengan pengetahuan baik pada pekerja bawah air ada sebanyak 5 orang $(83 \%)$. 
Tabel 2. Distribusi Responden Berdasarkan Pengetahuan Penyelaman di PT Aquamarine Divindo Inspection Sidoarjo Tahun 2017

\begin{tabular}{lcc}
\hline \multicolumn{1}{r}{ Pengetahuan } & n & \% \\
\hline Baik & 5 & 83 \\
Buruk & 1 & 17 \\
\hline Total & 6 & 100 \\
\hline
\end{tabular}

Pengetahuan responden berdasarkan pengetahuan menyelam yang telah didapatkan dari pelatihan atau training khusus untuk mendapatkan sertifikasi yang berstandar internasional. Pengetahuan responden yang meliputi pengetahuan mengenai keadaan lingkungan, mereka harus bisa beradaptasi dengan lingkungan laut yang digunakan dalam objek pekerjaan. Lingkungan laut dapat berupa lingkungan berlumpur, berkarang, atau banyak binatang buas di sekitar laut. Pengetahuan yang paling berhubungan dengan gangguan pendengaran adalah pengetahuan teknik menyelam.

Teknik menyelam yang paling berpengaruh adalah teknik equalizing. Teknik tersebut sangat memengaruhi gangguan pendengaran, karena apabila seseorang terlambat melakukan teknik equalizing, maka mereka akan naik ke permukaan laut untuk mengambil nafas, tetapi ternyata cara itulah yang menyebabkan adanya perbedaan tekanan yang cukup besar dan bersifat fatal bagi pekerja.

Responden dengan pengetahuan menyelam buruk yaitu pekerja bawah air yang baru memulai karir dalam bidang konstruksi bawah air, sehingga kurangnya pengalaman membuat pekerja mengalami gangguan pendengaran tuli sedang.

pada tabel 3 didapatkan Nilai Ambang Dengar (NAD) pekerja bawah air di PT Aquamarine Divindo Inspection Sidoarjo. Peneliti mengklasifikasikan nilai ambang dengar pada responden yang didasarkan pada klasifikasi menurut WHO, 1980. Pemeriksaan telinga pada pekerja bawah air menggunakan audiometri oleh salah satu laboratorium kesehatan. Pengklasifikasian dari WHO lebih banyak digunakan oleh beberapa penelitian. Hasil dari penelitian, paling banyak responden dengan gangguan pendengaran tuli ringan yaitu sebanyak $50 \%$.

Selanjutnya, dilakukan pengujian statistika menggunakan uji Chi Square untuk kedua variabel. Hasil uji yang dilakukan, didapatkan signifikasi koefisien kontingensi sebesar 0,05 . Nilai $\alpha=0,05$ $(5 \%)$, maka nilai signifikasi koefisien kontingensi
Tabel 3. Distribusi Responden Berdasarkan Hasil Pemeriksaan Audiometridi PT Aquamarine Divindo Inspection Sidoarjo Tahun 2017

\begin{tabular}{lcc}
\hline Gangguan Pendengaran & n & \% \\
\hline Normal & 2 & $33 \%$ \\
Tuli ringan & 3 & $50 \%$ \\
tuli sedang & 1 & $17 \%$ \\
\hline Total & 6 & $100 \%$ \\
\hline
\end{tabular}

sama dengan $\alpha$ maka dapat dikatakan bahwa Ho ditolak, yang artinya terdapat hubungan antara pengetahuan menyelam dengan gangguan pendengaran pada pekerja bawah air di PT Aquamarine Divindo Inspection Sidoarjo.

\section{PEMBAHASAN}

PT Aquamarine Divindo Inspection Sidoarjo merupakan perusahaan yang berperan dalam bidang konstruksi bawah air, biasanya perusahaan ini menangani perbaikan kapal atau lambung kapal, serta penyambungan pipa minyak dan gas di dalam laut. Perusahaan ini tidak mempunyai program pemeriksaan kesehatan berkala kepada pekerja. Pemeriksaan kesehatan diatur dalam Peraturan Menteri Tenaga Kerja dan Transmigrasi No. Per. 02/MEN/1980 yang berbunyi perusahaan yang diwajibkan melakukan pemeriksaan kesehatan wajib membuat rencana pemeriksaan kesehatan sebelum bekerja, berkala dan pemeriksaan kesehatan khusus. PT Aquamarine Divindo Inspection Sidoarjo termasuk dalam perusahaan yang seharusnya memiliki program pemeriksaan kesehatan karena mengingat risiko yang cukup tinggi pada pekerja karena paparan pekerjaan dengan jangka waktu yang cukup lama.

Responden dengan total populasi 6 orang merupakan responden dengan pekerjaan tetap atau biasa disebut sebagai pegawai tetap dari perusahaan PT Aquamarine Divindo Inspection Sidoarjo.

Responden sebagian besar memiliki pengetahuan menyelam baik. Dan hasil pemeriksaan menunjukkan bahwa pekerja bawah air lebih banyak memiliki gangguan telinga tuli ringan sebanyak 50\% dari total populasi responden. Responden dengan gangguan pendengaran tuli ringan masih termasuk ke dalam golongan normal dengan kata lain tidak terlalu parah dan berbahaya bagi pekerja bawah air.

Pengetahuan responden termasuk dalam pengetahuan mengenai cara menyelam dengan 
baik dan benar. Perusahaan sudah memiliki standar penyelaman bagi penyelam yang berstandar internasional, dan sudah memiliki sertifikasi yang diakui. Pekerja bawah air yang meliputi teknisi, operation, dan pengelas bawah air harus memiliki sertifikasi di bidangnya masing-masing. Sertifikasi pada bidangnya masing-masing sudah harus diakui oleh internasional dan merupakan standar perusahaan pada saat rekruitmen.

Pengetahuan pada responden meliputi pengetahuan mengenai penggunaan alat pelindung diri, teknik ekualising, cara mengetahui keadaan, kondisi laut sekitar objek pekerjaan, dan sikap kerja yang tidak aman. Pengetahuan yang paling penting merupakan pengetahuan mengenai teknik ekualising pekerja bawah air, karena sangat berpengaruh besar terhadap gangguan pendengaran. Penyelam terlambat dalam melakukan teknik equalizing, maka penyelam tersebut akan naik ke atas permukaan laut dengan cepat dan terjadi gangguan pendengaran karena perbedaan tekanan yang cukup signifikan.

Menurut hasil penelitian Dharmawirawan dan Modjo (2012), pada nelayan tradisional di Kepulauan Seribu, salah satu yang termasuk ke dalam identifikasi bahaya keselamatan dan kesehatan kerja adalah pengetahuan nelayan kompresor mengenai safety dive yang rendah. Pengetahuan tersebut berdampak pada adanya gangguan dan penyakit akibat kerja pada penyelaman.

Penggunaan alat pelindung diri seperti kaca mata dan kompresor juga dapat menyebabkan terjadinya gangguan telinga dan penyakit barotrauma telinga pada penyelam. Sebanyak $60 \%$ nelayan yang tidak menggunakan kompresor maupun kaca mata menderita kejadian barotrauma berat, sementara total responden yang mengalami kejadian barotrauma berarti pada penelitian tersebut berjumlah $53,3 \%$ (Irhamdi dkk, 2016).

Banyaknya pengetahuan dapat dilihat dari pendidikan pekerja bawah air, semakin tinggi pendidikan maka tingkat pengetahuan semakin besar.
Sebaliknya, jika semakin rendahnya pendidikan maka tingkat pengetahuan semakin kurang. Selain itu pengetahuan mengenai menyelam bisa didapatkan juga dari pengalaman pekerjaan responden, semakin banyak dan lamanya pengalaman, maka akan semakin mengetahui teknik penyelaman yang akan dilakukan.

Responden paling banyak mengalami gangguan pendengaran tuli ringan dengan pengetahuan menyelam baik yaitu responden yang mengalami gangguan tuli ringan dalam batas normal. Baik atau buruknya pengetahuan didapatkan dari pengalaman dan lama kerja responden selama bekerja di bidang konstruksi bawah air. Sementara, buruknya pengetahuan biasanya dikarenakan kurang adanya pelatihan dan briefing mengenai cara penyelaman yang benar dan aman. Sebenarnya, semua pekerja bawah air memiliki pengetahuan yang sama karena mereka memiliki sertifikasi yang berstandar internasional, hanya untuk media pengimplementasiannya saja yang berbeda untuk setiap orang.

\section{SIMPULAN}

\section{DAFTAR PUSTAKA}

Dharmawirawan, D.A., Modjo, R., 2012. Identifikasi Bahaya Keselamatan dan Kesehatan Kerja pada Penangkapan Ikan Nelayan Muroami. Kesmas: National Public Health Journal, [e-Jurnal] 6(4), pp.185-192

Ekawati, T., 2005. Analisis Faktor Risiko Barotrauma Membrana Timpani Pada Nelayan Penyelam Tradisional Di Kecamatan Semarang Utara Kota Semarang . Tesis. Semarang: Program Pascasarjana Universitas Diponegoro

Irhamdi, A., Soulisa, J. And Latuconsina, L., 2016. Hubungan Pengunaan Alat Penyelam Tradisional Dengan Kejadian Barotrauma. Global Health

Tabel 4. Distribusi Pengetahuan Penyelaman dengan Gangguan Pendengaran di PT Aquamarine Divindo Inspection Sidoarjo Tahun 2017

\begin{tabular}{|c|c|c|c|c|c|c|c|c|}
\hline \multirow{3}{*}{ Pengetahuan } & \multicolumn{6}{|c|}{ Gangguan Pendengaran } & \multirow{2}{*}{\multicolumn{2}{|c|}{ Total }} \\
\hline & \multicolumn{2}{|c|}{ Normal } & \multicolumn{2}{|c|}{ Tuli Ringan } & \multicolumn{2}{|c|}{ Tuli Sedang } & & \\
\hline & $\mathbf{n}$ & $\%$ & $\mathrm{n}$ & $\%$ & $\mathbf{n}$ & $\%$ & $\mathbf{N}$ & $\%$ \\
\hline Baik & 2 & 40 & 3 & 60 & - & - & 5 & 100 \\
\hline Buruk & - & - & - & - & 1 & 100 & 1 & 100 \\
\hline Total & 2 & 33.3 & 3 & 50 & 1 & 16.7 & 6 & 100 \\
\hline
\end{tabular}


Science (Ghs), [e-Journal] 1(1): pp. 30-35

Jamsostek P., 2012. Laporan Tahunan 2012. Jakarta: PT. Jamsostek

Kristianto, W., 2012. Gambaran Gangguan Pendengaran Pada Penyelam TNI Angkatan Laut. Skripsi. Depok: Fakultas Keperawatan Universitas Indonesia

Lazwar, F., 2015. Hubungan Tipe Kepribadian dan Stressor Lingkungan Kerja dengan Stres Kerja pada Penyelam di PT. Advanced Offshore Services. Skripsi. Surabaya: Fakultas Kesehatan Masyarakat Universitas Airlangga

Peraturan Menteri Tenaga Kerja Dan Transmigrasi No. Per.02/MEN/1980. Tentang Pemeriksaan Kesehatan Tenaga Kerja dalam Penyelenggaraan Keselamatan Kerja. Jakarta: Menteri Tenaga Kerja dan Transmigrasi

Rijadi, R., 2009. Ilmu Kesehatan Penyelaman dan Hiperbarik. Jakarta: Lembaga Kesehatan Kelautan TNI AL
Sukbar, S., Dupai, L. And Munandar, S., 2016. Hubungan Aktivitas Penyelam Dengan Kapasitas Vital Paru Pada Pekerja Nelatan Di Desa Torobulu Kecamatan Laeya Kabupaten Konawe Selatan Tahun 2016. Jurnal Ilmiah Mahasiswa Kesehatan Masyarakat, [e-Jurnal] 1(2): pp. 1-9

Suma'mur., 1991. Higiene Perusahaan dan Kesehatan Kerja. Jakarta: Haji Masagung

Susanto, S., 2010. Risiko Gangguan Pendengaran Pada Neonatus Hiperbilirubinemia. Tesis. Semarang: Magister Ilmu Biomedik dan Fakultas Kedokteran Universitas Diponegoro

Syafrudin, S.K., 2015. Hubungan Intensitas Bunyi dengan Kejadian Sensorineural Hearing-Loss di Salah Satu Pabrik Tekstil di Kabupaten Bandung. Skripsi. Bandung: Fakultas Kedokteran Universitas Islam Bandung

Undang-Undang Republik Indonesia Nomor 1 tahun 1970 tentang Keselamatan Kerja. Lembaran Negara RI Tahun 2003, No. 38. Jakarta: Sekretariat Negara 